\title{
On Effectively Foster Children's Early Reading Ability
}

\author{
Jie $\mathrm{Lu}^{1, \mathrm{a}}$ \\ ${ }^{1}$ Beihua University Teacher's College, Jilin, Jilin, China \\ a13961671@qq.com
}

Keywords: children; early reading; preschool education

\begin{abstract}
Preschool education is not only an initial stage for children to receive school education, but also a crucial period for children to develop reading habit, strengthen reading ability, stimulate reading motivation and master reading skills .Therefore, parents along with teachers should attach great importance to the essential role early reading plays in the growing stage of children. Firm foundation was supposed to be laid of children's learning and growth on the basis of updating the concept of education, grasping the rules and trends, focusing on stimulating interest and using scientific methods to carry out the effective cultivation of children are early reading ability.
\end{abstract}

\section{Introduction}

Early reading is crucial for children to learn language, which is of great importance and has great effect on improving their language ability. Early reading has been included in preschool education target system, which is elaborated in "Guidelines for Kindergarten Education (For Trial)" promulgated by the Ministry of Education. As is explicitly pointed out in the Guideline, "cultivating interests in listening to stories and reading books" should be regarded as one of essential tasks for children's education [1]. Meanwhile, as the education requirement and content of language development, it is regulated clearly that "children should be guided to read excellent children literacy books so that they are able to appreciate abundant and beautiful language and understand what described in the books profoundly by participating in a variety of activities and "Children's interests in reading, books and writing are expected to be aroused by such ways as drawing and reading." As a result, cultivating children's early reading ability in their preschool stage is an important content of the work for preschool teachers, which should become an important research topic and content of education reform on preschool education.

\section{Far-Reaching Significance and Meaning of Early Reading for Children Growth and Progress}

It benefits children's language development. Language ability is essential for children development, in that good language ability can not only help children to establish confidence, but also aid children to express themselves clearly and enhance their communication ability. In addition, early reading is helpful for children to learn listening, expressing as well as appreciating and understanding [2]. Therefore, developing children's early reading ability is a way to improve their language ability.

\section{It benefits children's language development}

Language ability is essential for children development, in that good language ability can not only help children to establish confidence, but also aid children to express themselves clearly and enhance their communication ability. In addition, early reading is helpful for children to learn listening, expressing as well as appreciating and understanding. Therefore, developing children's early reading ability is a way to improve their language ability.

\section{It is good for children's psychological heath}

Psychological health education is prominent in children's growth, for it does not exist in children's early development, but exist in their whole growth process. Fostering children's early 
reading ability can lead to sound mental development, furthermore, it can result in children's comprehensive development in terms of virtue, wisdom and health.

\section{It is helpful to children's intelligence}

Intelligence plays an important role in children's comprehensive development education. Children's intelligence development consists of comprehension development, deduction, judgment development and imagination development. Children's intelligence will grow together with the reading ability by early reading. By early reading, children are capable of understanding the common connection between things, utilizing analyzing and compounding ability and making either active or passive evaluation, which is beneficial to improvement on children's judgement , comprehension and description.

\section{It is in favor of children's emotion and social development}

Emotion is crucial for children's growth, because it is an importance index to measure children's mental health. children's sociality originally come into form as soon as they enter into the society, and tend to mature with the children's growth. Moreover, early reading place an importance part in spurring children's sound emotion and social matured, especially in behavior control and emotion control.

\section{Methods to Cultivating Children's Reading Ability}

\section{Creating pleasure environment to arouse reading interest}

Creating pleasure environment to arouse reading interest is significant to foster children's early reading ability. Environment can shape personality and change personality as well. In ancient china, there was a person named Mencius, whose mother moved her home three times to better Mencius education environment. This story elaborated to us the great effect environment have on a person's growth. The popular methods to create pleasure environment in order to stimulate children's reading interest mainly include setting up happy reading rooms, reading wall and news releasing wall and so on. Happy reading rooms are designed for creating more opportunities for children to read books, spurring strong interest of reading, making children love reading. Like reading rooms, reading walls are also aimed to improve children's reading interest. However, reading walls are more vivid and more attractive which is rather different from reading rooms. News wall is usually used to release good deeds occurred in children's class and interesting things impressed children, which enable children get know of model and model behavior around them and eventually increase their interest in reading.

\section{Carrying out various activities to help children master reading skills}

Various ways can be adopted in order to cultivate early reading skills, among which activities are most effective and acceptable way. The attention should be paid not only to children's understanding of written language but also to the ways to reading and grasping reading skills. For example, teachers can adopt activities concerning ordering pictures, in which teacher disorder the pictures related to some topic, then ask the children to find out the connection between the pictures and attempt to arrange the pictures in accordance with certain logical order by themselves. thus, children's logical analytic ability and reading ability can be improved. Asking children to cut the pictures they like off the old books and encourage children to edit their own books according to their imagination and originality, teachers can also organize children to DIY books. This kind of activities can foster children's views of beauty as well as train their practical ability.

\section{Reading effectively by the aid of a variety of activity forms}

Forms always serve for content. The purpose of adopting various activity forms is to make reading more effectively. So when selecting activity form, teachers are bound to figure out the expected goal of the activity clearly [3]. According to the aims of early reading activity, teachers should train the children's reading ability with specific plan and goal. Moreover, designing reading activity, teachers also need to take into account of children's accept ability and difference characteristics of different individual in order that all the children's motivation could be activated 
to join in the activity. Team reading and entertaining reading are good examples for this. One of the advantages of team reading is its strong attraction. A typical phenomenon happened frequently is a child read a lot of books, but most of the reading is as simple as looking at pictures. This kind of reading activity can hardly be effective. In fact, the reason for that is simple. The child read isolated, he cannot find a company with whom he communicates. His reads with no interaction. This can be overcome by team reading . children in a team can share their reading experience and review books together, which make reading activity more effectively.

\section{Adopting practical operation methods to urge children to master proper reading skills}

Teaching children to grasp reading skills is extremely important, which the premier to carry out children's reading activity. Reading skills come into shape because of more repeated practices than teachers 'and parents' instructions. Training children to grasp reading skills should follow such rules. First, guide children to read in order, that is , a book should be read in the order of from left to right and from up to down. Second, lay emphasis on understanding the connection between word and pictures. In another word, direct children to learn the meaning of related words, require them to know the words as well as understand the pictures. Third, the diversity of language and words should be shown to children. we can express a sentence in different ways. Different people came from different country use different language and expressions. Although people use different language, the culture of mankind is compatible [4].

\section{Cooperating closely between parents and kindergarten to develop children's early reading ability by way of great parenting reading environment}

Cultivating children's early reading ability is the responsibility of both kindergarten and parents, which need close cooperation and co- effort made by kindergarten and parents. Parents are the first teacher of child, parents' behavior have profound effect on child. In normal times, parents should communicate with kindergarten actively, get know of children's performance in time and create a proper reading environment for children together with kindergarten[5].

\section{Strengthening communication and reaching consensus}

Reaching consensus by regular communication made by kindergarten with parents is necessary for children's development, especially for children's reading ability development. Kindergarten can inform the children's performance to parents by holding parents meeting, in turn, parents can report the children's performance at home to kindergarten [6]. Communication and interaction between the two sides can be strengthened by this way. In addition, kindergarten can impart the appropriate concept of guiding children reading to parents, enables parents to grasp guiding methods of correct reading by various ways as poster, open day to parents, parents consultation and so on .

\section{Establishing material rooms to encourage parents to lend these materials}

Since children like books and like more reading stories, parents can develop children's reading interest by reading story books with children. as for kindergarten, setting up material rooms to provide story books or other reading materials children like is a good idea. Parents can borrow the books regularly. Family should take advantage of every chance to help children read,make them understand the relation between written language and oral language, and improve their comprehensive ability.

\section{Fostering children's good habit by employing all kinds of modes}

With the advert for mankind to information society, information net has access to every family. Internet is changing people's life style and providing modern education methods for us as well. Parents should take full advantage of internet resource and assist children to form early reading interest and habit via a wide range of modes. Moreover, children are likely to be enthusiastic to games. Therefore, parents can teach children some knowledge in the form of games. That is a good way to help children to form early reading habit and develop their reading ability. 


\section{References}

[1] Hong Xuehua, On cultivating children's early reading ability [J] ,China out school education, 2010, (S2).

[2] Zhang Lingling, Children's language education [N]. Guangyuan daily, 2012-01-10.

[3] Liang Jiaping, Discussion on instruction of early childhood reading strategies of primary school science teachers ([J].Forum),2012 (07):175.

[4] Zheng Xiaoli, Analysis training method of children's early reading ability [J]. The era of Education, Education, 2012 (06): 161.

[5] Chen Shuzhen, Based on the language teaching, reading ability development of enlightenment education [J].Forum, 2012 (15): $193 \sim 194$.

[6] Yang shengnan, New research on childhood language[J], Out school education in China, 2012, (2). 